\title{
Imunidades Diplomáticas e Certos Tipos de Contrato de Trabalho - As convenções de Viena de 1961 e de 1963 sobre "Relações Diplomáticas" e "Relações Consulares" ${ }^{t \prime}$.
}

\author{
Georgette N. Nazo \\ Professor Assistente-Doutor de Direito In- \\ ternacional na Faculdade de Direito da \\ Universidade de São Paulo.
}

Compulsando alguns números da LTR, encontramos artigos doutrinários e decisóes trabalhistas que nos deram um interesse maior em contribuir para o esclarecimento de uma questão que tem causado oscilações por parte de especialistas e dificuldades injustificáveis aos Juízes do Trabalho para solucionar certas relações empregatícias, oriundas de contratos formalizados dentro do setor diplomático.

Se, de um lado, OSIRIS RochA (LTR 37/600) eminente mestre do Direito Internacional Privado e Juiz do Trabalho em Belo Horizonte, reconheceu que suas anteriores concepções a respeito da competência da Justiça do Trabalho para dirimir certos contratos de trabalho, precisavam de distinções imprescindíveis, modificando seu ponto de vista, de outro lado, Gerson DE BRITTo Mello Boson, também professor de Direito Internacional em Minas Gerais, em artigo publicado na LTR 35/599 teceu magníficas ponderações a respeito da "Imunidade de jurisdição do Estado e as relações de Trabalho".

Todavia, a despeito das informações robustas do Ministro G. E. Do NASCIMENTo E SilVA que integrou a delegação brasileira à "Convenção de Viena sobre Relações Diplomáticas" em 1961, sob os auspícios da oNU e do excelente estudo de LUIZ ROBERTo REZENDE PUECH, sobre Imunidade de Jurisdição e os

* Aula proferida no curso de sua programação para a Área V de Especialização em Direito Internacional Privado do Trabalho, na Faculdade do Direito do Largo de São Francisco, 1975. 
Direitos Sociais (Na Vivência do Direito Social - Edit. Resenha Universitária Ltda., S.P., 1975), ainda assim, os Juízes da Justiça do Trabalho encontram dificuldades na aplicação do texto desta Convenção que foi aprovada pelo Brasil, ratificada pelo Decreto-Legislativo n. ${ }^{\circ} 103$ de 1964, depositada e ratificada pela oNU em 1965 e promulgada entre nós, através do Decreto-Executivo n. $^{\circ} 56.435$ de 08 de Junho de 1965 . E, ao lado desta, também a ensejar certo desconforto aos Juízes Trabalhistas, outra Convenção de Viena sobre Relações Consulares (1963) vem ocasionando julgados e interpretações díspares, inseguros como se encontram os integrantes do Colegiado Trabalhista de determinados princípios gerais, quer de Direito Internacional Público, quer de Direito Internacional Privado, e, porque não dizer, também, da própria teoria geral do processo e da Constituição da República Federativa do Brasil com o seu Direito Constitucional Processual, descambando, por vezes, para a teoria da reciprocidade, que nada tem a ver com a questão.

No intuito, somente, de prestar uma simples colaboração à colocação do problema, tentaremos enfocá-lo através do que reputamos necessário distinguir com referência às imunidades diplomáticas, a certos tipos de contratos de trabalho em Embaixadas e Consulados, através do que existe nos textos de lei vigente entre nós.

\section{Imunidades Diplomáticas.}

Sem que se faça a distinção entre "jus imperii" e "jus gestionis" não se conseguirá enfrentar essa questão.

O velho adágio latino: "par in parem non habet judicium" define bem o "jus imperii" de um Estado. E a pessoa jurídica de Direito Interno e Internacional investida de plenos poderes de autodeterminação e autodelimitação desses mesmos poderes que refletem a sua soberania, quer na ordem jurídica interna, quer internacional. Como decorrência dessa Soberania, o Estado atuando com "jus imperii" não pode basear-se em convenções ou tratados internacionais, pois isso implicará numa limitação à sua própria razão de ser.

A independência recíproca dos Éstados Soberanos fundamenta-se na imunidade de sua jurisdição territorial.

Princípio universalmente conhecido, quer como decorrência de um costume tradicional do Direito das Gentes, ou de um uso internacional que permita a coexistência harmônica 
na ordem jurídica internacional, procuram os Estados delimitar suas atribuições jurisdicionais no espaço, mas conservam as imunidades inerentes às mesmas.

Imunidades de jurisdição e de execução, embora estreitamente ligadas, não se confundem. Na primeira, o Estado pode limitar a competência ordinária de seus Tribunais, subtraindo-lhes a apreciação de determinados assuntos que digam respeito à jurisdição de um outro Estado Soberano. Ao passo que na segunda, ainda que pareça criar barreiras à eficácia de um direito reconhecido por jurisdição estrangeira, o Estado dela se serve, ao verificar a impossibilidade jurídica interna de efetivamente poder executar o julgado alienígena.

Imunidades de jurisdição e de execução, como salienta PIERRe Bourel (Rép. Dalloz de Droit International, verbete: Immunité), são tradicionalmente consideradas como aspectos particulares das imunidades diplomáticas.

0 assunto, assim examinado, toca nas fronteiras do direito, da política, do direito interno e internacional, do direito público e do privado, trazendo dificuldades à criação de uma teoria geral a respeito.

$\mathrm{E}$, se analisarmos certas posições doutrinárias estrangeiras, veremos que alguns autores se inclinam a abolir as imunidades diplomáticas (consulte-se LAUTERPACHT, The Problem of Jurisdictionnal Immunities of Foreign States, B. Y. B., 1961) ; outros entendem que se deva falar em incompetências de atribuições (consulte-se NiBOYET, em artigo publicado na Rev. Crit., 1950 - p. 139 e seguintes - Immunité de Juridiction et Incompétence d'attribution onde reconhece não ter feito distinção suficiente no seu Traité, t. V, v. 1, n. ${ }^{\circ} 1759$ e segs. e, na mesma Revista, 1951, p. $209 / 225$ e $449 / 470$, as aspirações de FrEYRIA no sentido de uma regulamentação adequada à matéria, discorrendo sobre: Les limites de l'immunité de juridiction et d'exécution des Etats Etrangers). No entanto, CARABIBER, em artigo publicado no Journal de D. International, 1952 , p. 440 e seguintes, prefere colocar o problema, no campo das jurisdições internacionais (Le Concept des immunités de juridiction doit-il être revisé et dans quel sens?").

Como pessoa jurídica, o Estado é representado, oficialmente, por pessoas físicas que, atuando com "jus imperii", gozam das imunidades necessárias ao exercício de suas atribuições. Assim o Chefe de Estado (Presidente da República ou com qualquer outra nomenclatura, rei, imperador, etc.) é de designação de direito interno de cada sistema jurídico e, 
óbviamente, é o representante máximo de um Estado, embora, pelo seu próprio direito interno, possa sofrer atribuições limitadas.

Junto com o Chefe de Estado, desempenham também funções de representantes de um governo, os Ministros de Estado, o Ministro das Relações Exteriores, os Agentes Diplomáticos e os Cônsules, todos eles, por delegação, também investidos de "jus imperii", nos limites de suas funções específicas, portanto, mais restritas, e gozando das imunidades e prerrogativas concernentes a tais funções: inviolabilidade da pessoa e de seus documentos, da sua residência, isenção de impostos diretos e direitos aduaneiros, de jurisdição territorial, quer em matéria civil, quer criminal, à exceção dos casos em que aceitam a jurisdição estrangeira, ou litigam sobre bens imóveis situados no estrangeiro, como partes interessadas, ou em ações propostas contra eles, como legatários ou herdeiros; essas imunidades se estendem aos membros de sua família.

Atuando no estrangeiro, investidos desse "jus imperii", esses representantes de um governo gozam de imunidade diplomática em conseqüência da própria cortesia internacional entre Estados, e aqui sim, pode-se falar em reciprocidade de tratamento entre Estados, escoimando-se a doutrina moderna do princípio da extraterritorialidade que teve, em HUGo GrotiUs, seu maior apologista.

No entanto, os Agentes Diplomáticos, se designados por um Governo para exercer, como seu representante, direitos e interesses ligados a seu país, essa reciprocidade de tratamentos é chamada, como bem lembra, ACcioly, de "Legação" (ativa, quando o Estado envia o seu agente; e, passiva, quando recebe representantes de outros governos).

Mas, esse "jus imperii" que, de início era absoluto, sofreu, ao correr dos tempos, um abrandamento, pela própria necessidade do comércio internacional, do intercâmbio entre Estados Soberanos, para permitir uma aproximação maior no seu relacionamento e uma interdependência mais estreita, por conveniências econômicas, jurídicas, políticas e sociais. Com isso, não perdem os Estados a sua imunidade de jurisdição no campo internacional em seus territórios, o que viria ferir sua própria soberania, a sua ordem jurídica interna e também a ordem jurídica internacional.

Todavia, o Estado não atua somente através do "jus imperii". Pratica, ao mesmo tempo, o "jus gestionis" e nessa 
maneira de agir, ele desce do seu "jus imperii" e negocia, no comércio e na política internacional, como se praticasse atos de direito privado.

Não é estranho, portanto, que o estudioso que se engaja nos meandros do direito do comércio internacional, que vem adquirindo, nestes últimos anos, ênfase especial por parte dos internacionalistas, encontre, a todo instante, o exemplo característico da figura do Estado-comerciante. O Estado age, no campo das atividades negociais, na esfera internacional, ao realizar certos tipos de transações com pessoas físicas, ou jurídicas estrangeiras, tal como o comerciante comum, no setor do direito privado.

Exemplo característico encontramos em França. CHARLES RousSEAU, defensor ferrenho da imunidade absoluta, precisou vergar-se diante da realidade das negociações mantidas com a Rússia em 1949 e 1951, através de acordos, vez que não se pode avocar a imunidade estatal nessa extensão extrema, em atos de gestão praticados pelos agentes russos em território francês, a despeito de existir monopólio de comércio externo, por parte do Estado Russo.

Daí podermos afirmar que, em se falando de atos de gestão, é possível haver tratados e convenções internacionais especiais e até mesmo, regionais entre Estados.

Se, em França, Rousseau e LouIs CAVARÉ sentiram o problema e aceitaram esse abrandamento da imunidade estatal através dos atos de gestão, em outros sistemas jurídicos, a doutrina também se orientou neste sentido. Apenas como lembrança: na Suiça, PAUL, GUGGENNHEIM ; na Itália, BALLAdore PALLIERE; na Alemanha, ALFRED VERDRoss ; na América Latina, LUCIo QUINTANA e BoLIINI SHAW, e, entre nós, o sempre atual HILDEBRANDo ACcioly. Mas, é digno de realce que todos eles, cujas obras surgiram nesses últimos vinte anos, revigoraram tese já defendida em 1923, por ANDRÉ WIESS, em artigo publicado no Recueil des Cours, sobre Compétence ou Incompétence des Tribunaux à l'egard des États Etrangers (I-548/9).

Contemporaneamente às idéias continentais, a "International Law Association", em 1952, em reunião realizada em Lucerna, aprovou, a seguinte Resolução:

“... o princípio da imunidade de Jurisdição dos Estados estrangeiros está em vias de cair em desuso, quando os Estados empreendem operações comerciais ou outros atos de direito privado". 
E, com efeito, nas Convenções de Viena sobre Relações Diplomáticas e Consulares, aprovadas em 1961 e 1963, cujo objetivo primordial foi o de substituir o velho Estatuto de Viena de 1815, cuja Convenção de 18 de março foi complementada em 21 de novembro de 1918, no Congresso de Aix-le-Chapelle, ou de Agrisgrana sobre a preservação dos bens e das pessoas dos Agentes Diplomáticos, vamos encontrar diversos artigos, mostrando que se o Estado Estrangeiro contrata serviços de elementos nacionais do Estado de recepção, o vínculo empregatício se estabelece na conformidade das leis e dos regulamentos deste último, pois o Estado estrangeiro atua pelo seu "jus gestionis" e não investido de "jus imperii".

Semelhantes "Convenções de Viena" de 1961 e de 1963, em vigor, no Brasil, como vimos, desde 8 de junho de 1965, são, hoje, lei interna, aplicável não somente aos chefes de missões diplomáticas estrangeiras, mas envolvendo todos os membros do pessoal diplomático e consular.

Entretanto, há que se fazer uma ressalva no tocante aos "funcionários consulares, administrativos ou agentes oficiais sem caráter diplomático".

São conhecidas as duas categorias de cônsules: $1-o s$ "electi", ou honorários: mandatários dos países que os elegem, mas não são funcionários deste, nem do Estado receptor ; 2 os "missi", ou de carreira, que são efetivos do Estado que os nomeia, podendo ser nacionais do mesmo, recebendo deste os proventos e se dedicando, exclusivamente, à atividade consular de natureza local (regional ou distrital).

Tanto numa, como noutra Convenção de Viena, sobre o assunto, aprovadas, como dissemos, por nós, em 1965, ficaram definidas, não somente, as chamadas "missões diplomáticas" e "repartições consulares", como também, todo o pessoal que integra ambas as repartições estrangeiras, acreditadas num território de recepção das mesmas.

Diversos tratadistas já se ocuparam em analisar os textos destas Convenções, de sorte a circunscreverem até onde se pode conceber a imunidade diplomática.

Para nós, o que realmente interessa neste despretensioso estudo, é, tão-somente analisar a situação de certos contratos de trabalho, firmados através de Embaixadas e Consulados, aqui acreditados e que não estão acobertados por imunidade diplomática. 


\section{Contratos de Trabalho de Natureza Negocial, Isentos de Imunidades Diplomáticas.}

Quer em "missões diplomáticas", como em "repartições consulares", são realizados contratos de emprego que não estão sujeitos à jurisdição do país acreditante.

Com efeito, o surto comercial de nossos tempos, a expansão que sistemas jurídicos estrangeiros vêm imprimindo em diversos setores de mão-de-obra nacional, abrindo agências de turismo e respectivos escritórios de propaganda, criando escolas, cursos de intercâmbio cultural, recrutamento técnico, a convocar, mesmo dentro de Embaixadas e Consulados, pessoal para exercer atividades administrativas e domésticas, com fins lucrativos, melhor dizendo, assalariados, muitas vezes, até, com vinculação empregatícia particular a um membro dessas entidades diplomáticas, não há que se cogitar, aqui, em imunidade de jurisdição do empregador, especialmente se contratam brasileiros, ou estrangeiros que estão radicados no país.

Existe, isso sim, por parte de tais empregadores, uma atividade negocial decorrente do "jus gestionis" que exercem como representantes dos países acreditantes. Nestas condições, o contrato de trabalho se perfaz na conformidade de nossas leis territoriais, de acordo com a legislação interna brasileira.

Se levarmos em conta o art. $9 .^{\circ}$ da Lei de Introdução ao Código Civil, com a implícita regra "locus regit actum" (sem maiores e aprofundadas ponderações quanto à substância e à forma do ato), bem como, o caput do seu artigo 12 e o artigo 17, combinados com o artigo 88 do Código de Processo Civil em seus diversos itens, vamos aí encontrar fixada a competência internacional da Justiça Brasileira, sendo o réu domiciliado no Brasil ou aqui tiver de ser cumprida a obrigação (contra-prestação do serviço), ou se tiver como "causa petendi": fato ocorrido no Brasil, ou ato praticado no Brasil, bem como a norma relativa à ordem pública, os bons costumes e soberania nacional.

Ora, como já dissemos antes, a jurisdição de um Estado, no espaço, pode ser exercida ilimitadamente perante outro Estado. Mas, se levarmos em consideração a harmonia da comunidade internacional, é corolário lógico que, toda a jurisdição de um Estado necessariamente sofre suas limitações, para que, como bem lembra AMILCAR DE CASTRo, possa ser efetivada. 
De outra parte, há que se cogitar, também, que é característica do Direito do Trabalho, o amparo ao trabalhador, atendendo-o nas suas necessidades sociais e previdenciárias, através de um intervencionismo cada vez mais evidente por parte do Estado, para que seja verdadeira a justiça social, tão bem lembrada nas Encíclicas Rerum Novarum, Quadragesimo Anno, Mater et Magistra.

A extensão dos direitos do trabalhador, não somente daqueles que, a princípio eram chamados hiposuficientes como também hoje, do trabalhador intelectual, deu margem à criação de um autêntico direito obreiro, com regulamentação internacional, através de organismos coletivos que buscaram, por meio de acordos internacionais, atender às exigências da classe operária em harmonia com as necessidades das classes empregadoras. Abandonou-se o liberalismo dos primeiros tempos e os Estados, hoje, intervêm diretamente nas relações de emprego, trazendo para o seu direito interno tudo aquilo que foi e tem sido objeto de encontros, congressos, resoluções, recomendações e acordos plurinacionais, para salvaguardar um dos direitos fundamentais da pessoa humana (a título de exemplos: a Carta do Atlântico, 1941, a Declaração de Filadelfia, 1944, a Carta das Nações Unidas, 45 e a Ata de Chapultepec, Carta de Bogotá, 48 e, especialmente, a Declaração Universal de Direitos Humanos).

Eis porque, se os Agentes Diplomáticos que, em três momentos tiveram regulamentadas suas atribuições (em Viena, em março de 1815, em Havana, em fevereiro de 1928 - cuja Convenção resultou da $6 .^{\mathrm{a}}$ Conferência Internacional Americana (ratificada pelo Brasil) e depois, novamente em Viena, em abril de 1961), os Consules também tiveram, através da história, diversas tentativas de codificação de seus direitos: a primeira delas, quando o Instituto de Direito Internacional se reuniu em Lausanne em 1888, adotando, depois, em 1896 a regulamentação das imunidades Consulares. No entanto, a princípio em acordos pluriregionais: assim, em 1927, a Comissão Pan-Americana de Juristas preparara um projeto, adotado, depois, em 1928 na Convenção de Havana, sobre as suas prerrogativas e funções; em 1949, a Comissão de Direito Internacional das Nações Unidas organizou também uma série de programações sobre imunidades e relações Consulares, para que fosse examinada em conferência internacional. 0 projeto, então elaborado, na Conferência das Nações Unidas, foi votado em Viena, 1963 (18/04), com a participação de 92 países, inclusive o Brasil, não sendo também alheio ao assunto, 
- Conselho Europeu que também elaborara projeto sobre relações consulares.

Disto tudo se conclui que as Convenções de Viena, de 1961 e 1963, ratificadas pelo Brasil em 1965, constituem, hoje, direito positivo interno, inserido no próprio texto da Constituição Federal que, já influenciada pelas recomendações expressas em Congressos Internacionais e da própria Organização Internacional do Trabalho (o.I.T., já trazia em seu bojo o princípio da exonomia, deixando aberto, no capítulo dos Direitos e Garantias Individuais, no título sobre a Ordem Econômica e Social, a segurança e liberdade de trabalho; cuidando, em seção própria, dentro do Capítulo Do Poder Judiciário, de fixar a competência dos Tribunais e Juízes do Trabalho para conciliar e julgar os dissídios individuais e coletivos entre empregados e empregadores.

Sendo assim, o recrutamento de brasileiros e de estrangeiros radicados no Brasil para, através de contrato de emprego, prestarem serviços nos territórios estrangeiros de Embaixadas e Consulados aqui recebidos, fica amparado pela Consolidação das Leis do Trabalho e Lei de Previdência Social, não só em decorrência da Lei Maior, mas como conseqüência das normas cogentes do Direito do Trabalho no Brasil, imperativas, de direito público interno, em consonância com as normas instrumentais da Lei de Introdução ao Código Civil Brasileiro.

E explicamos: na Constituição Federal estão as normas integradas do direito do trabalhador e aí também, definido o Direito Constitucional Processual que, na lição de JosÉ FREDERICo MARqUes, "é o conjunto de normas da Constituição que atinge ao processo em quaisquer de suas formas. As fontes deste, são, portanto, apenas regras da Constituição". No caso do Direito do Trabalho, a competência da Justiça do Trabalho está definida no art. 142.

A lei ordinária aplicável à espécie é a conjugação das normas do Direito Internacional Privado com a Consolidação das Leis do Trabalho. Isto porque, através do "jus gestionis", as Embaixadas e Consulados contratando nacionais ou estrangeiros aqui domiciliados, para determinadas atividades, subordinam-se à jurisdição brasileira, não só, para que não haja ofensa à ordem pública, à Soberania Nacional e aos bons costumes (art. 17 da L. Int. C. Civ.), como também, porque, tais contratos refletem uma atividade negocial que se insere na regra do art. $90^{\circ}$ da L. Int., pela própria força da lei do contrato como elemento de conexão. 
$\mathrm{E}$, sendo a competência, a medida da jurisdição, é curial que, devendo aqui ser cumprida a obrigação, ou sendo o réu aqui domiciliado, como vimos, há um entrelaçamento entre a C.L.T. e a norma do art. 12 da L. Introdução, reproduzida hoje, de modo mais explícito, no art. 88 do c.P.C. que, como normas de processo, ou instrumentais, determinam a lei a ser aplicável. $\mathrm{E}$ esta, indubitavelmente, é o direito material interno, expresso na Consolidação das Leis do Trabalho.

Apenas, para concluir, verificando-se os empasses jurisprudenciais criados na Justiça do Trabalho, em causas desta natureza, sentindo-se a confusão que os Juízes do Trabalho estão praticando, até agora, em 1975, ao pretenderem jogar para a Justiça Federal, matéria que lhe não compete decidir, por não envolver imunidades diplomáticas, a despeito das ponderações aqui trazidas, no intuito de esclarecer que tais contratos trabalhistas giram em torno do "jus gestionis" dos diplomatas e não do "jus imperii", melhor do que ninguém o Projeto de Código de Aplicação das Normas Jurídicas do sempre mestre HaROLDO VALLADÃo, em seu art. 63, trata das "Relações de Trabalho", "in verbis":

"Às relações de trabalho iniciadas, exercidas ou concluídas em território brasileiro, aplicam-se as leis brasileiras referentes a direitos, vantagens e garantias, mínimos, do empregado".

$\S$ único: "Dependendo tais direitos de prazo de atividade do empregado, será também computado - tempo da mesma decorrido no estrangeiro".

Nesse mesmo "Projeto" ao versar a matéria referente à "Lei Geral do Processo", e competência, no art. 67 § 1.0 letra " $d$ ", vem corroborar o que muitos que escreveram sobre este tema já sentiram: o desamparo em que ficariam os trabalhadores se precisassem postular seus direitos, não no Brasil, mas perante os Tribunais Estrangeiros, o que seria um absurdo, quando afirmando a competência da lei territorial para reger a forma, a competência e a representação judicial das partes, conclui:

art. 67 \& $10^{\circ}$ letra " $d ":$ Se apenas no Brasil for possível tornar efetivo o direito em causa".

Sem essa possibilidade de se tornar efetivo o direito em causa, nenhuma jurisdição sofreria as limitações indispensáveis, como já dissemos, apoiados na douta expressão de AMILCAR DE CASTRo, isto é, que possa ser efetivada. 